\title{
Discrete particle simulations of bubble-to-emulsion phase mass transfer in single-bubble fluidized beds
}

\section{Citation for published version (APA):}

Tan, L., Roghair, I., \& van Sint Annaland, M. (2017). Discrete particle simulations of bubble-to-emulsion phase mass transfer in single-bubble fluidized beds. Particuology, 33, 80-90.

https://doi.org/10.1016/j.partic.2016.09.008

DOI:

10.1016/j.partic.2016.09.008

Document status and date:

Published: 01/08/2017

\section{Document Version:}

Author's version before peer-review

\section{Please check the document version of this publication:}

- A submitted manuscript is the version of the article upon submission and before peer-review. There can be important differences between the submitted version and the official published version of record. People interested in the research are advised to contact the author for the final version of the publication, or visit the $\mathrm{DOI}$ to the publisher's website.

- The final author version and the galley proof are versions of the publication after peer review.

- The final published version features the final layout of the paper including the volume, issue and page numbers.

Link to publication

\section{General rights}

Copyright and moral rights for the publications made accessible in the public portal are retained by the authors and/or other copyright owners and it is a condition of accessing publications that users recognise and abide by the legal requirements associated with these rights.

- Users may download and print one copy of any publication from the public portal for the purpose of private study or research.

- You may not further distribute the material or use it for any profit-making activity or commercial gain

- You may freely distribute the URL identifying the publication in the public portal.

If the publication is distributed under the terms of Article 25fa of the Dutch Copyright Act, indicated by the "Taverne" license above, please follow below link for the End User Agreement:

www.tue.nl/taverne

Take down policy

If you believe that this document breaches copyright please contact us at:

openaccess@tue.nl

providing details and we will investigate your claim. 


\title{
Discrete particle simulations of bubble-to-emulsion phase mass transfer in single-bubble fluidized beds
}

\author{
Lianghui Tan ${ }^{\mathrm{a}}$, Ivo Roghair ${ }^{\mathrm{a}}$, Martin van Sint Annaland ${ }^{\mathrm{a}, *}$ \\ ${ }^{a}$ Chemical Process Intensification, Multiphase Reactors Group, Department of Chemical Engineering 8 \\ Chemistry, Eindhoven University of Technology, P.O. Box 513, 5600 MB Eindhoven, the Netherlands. T: +31 \\ (0)402472241, F: +31(0)402475833
}

\begin{abstract}
A classical Euler-Lagrangian model for gas-solid flows has been extended with gas component mass conservation equations, and has been used to obtain fundamental insights on bubble-toemulsion phase mass transfer in bubbling gas-solid fluidized beds. Simulations on injected, single rising bubbles under incipient fluidization conditions have been carried out, using both GeldartA and -B type particles. Comparisons between the phenomena observed in the simulations and various theoretical models used to derive phenomenological models have been performed, in order to challenge the assumptions underlying these phenomenological models. The bubbleto-emulsion phase mass transfer coefficients calculated for the simulations using Geldart-B type particles are in a good agreement with the predictions by the Davidson and Harrison (1963) model. The bubble-to-emulsion phase mass transfer coefficients for Geldart-A type particles are, however, much smaller than the predictions from theoretical models (e.g. Chiba and Kobayashi (1970)). The newly developed model allows a detailed analysis of various hydrodynamic aspects and their effect on the mass transfer characteristics in and around rising bubbles in fluidized beds.
\end{abstract}

Keywords: mass transfer, discrete particle model, fluidized beds, bubble-to-emulsion

\begin{tabular}{|ll|}
\hline Nomenclature & \\
$A$ & area, $\left[\mathrm{m}^{2}\right]$ \\
$c$ & number of species, $[-]$ \\
$d$ & particle diameter, $[\mathrm{m}]$ \\
$D_{b}$ & bubble diameter, $[\mathrm{m}]$
\end{tabular}

\footnotetext{
${ }^{*}$ corresponding author

Email address: M.v.SintAnnaland@tue.nl (Martin van Sint Annaland)
} 


\begin{tabular}{|c|c|}
\hline $\mathcal{D}$ & diffusion coefficient, $\left[\mathrm{m}^{2} / \mathrm{s}\right]$ \\
\hline$e$ & coefficient of restitution, [-] \\
\hline$f$ & volume fraction, [-] \\
\hline $\mathbf{F}_{\text {contact }, a}$ & contact force of particle $a,[\mathrm{~N}]$ \\
\hline $\mathrm{g}$ & gravitational acceleration, $\left[\mathrm{m} / \mathrm{s}^{2}\right]$ \\
\hline$I$ & moment of inertia, $\left[\mathrm{kg} \cdot \mathrm{m}^{2}\right]$ \\
\hline$k$ & spring stiffness, $[\mathrm{N} / \mathrm{m}]$ \\
\hline$K$ & mass transfer coefficient, $[/ \mathrm{s}]$ \\
\hline$m_{a}$ & particle mass, $[\mathrm{kg}]$ \\
\hline$M$ & molar mass, $[\mathrm{kg} / \mathrm{mol}]$ \\
\hline$N_{\mathrm{p}}$ & particle number, [-] \\
\hline$P$ & pressure, $[\mathrm{Pa}]$ \\
\hline$R$ & gas constant, $[\mathrm{J} / \mathrm{mol} \cdot \mathrm{K}]$ \\
\hline $\mathbf{S}_{p}$ & particle drag source term, $\left[\mathrm{N} / \mathrm{m}^{3}\right]$ \\
\hline$t$ & time, $[\mathrm{s}]$ \\
\hline$T$ & temperature, $[\mathrm{K}]$ \\
\hline $\mathbf{u}_{g}, \mathbf{v}_{a}$ & gas and solid velocity, $[\mathrm{m} / \mathrm{s}]$ \\
\hline$U$ & velocity, $[\mathrm{m} / \mathrm{s}]$ \\
\hline$V$ & volume, $\left[\mathrm{m}^{3}\right]$ \\
\hline$x$ & mole fraction, [-] \\
\hline$y$ & mass fraction, [-] \\
\hline \multicolumn{2}{|c|}{ Greek symbols } \\
\hline$\beta$ & inter-phase momentum exchange coefficient, $\left[\mathrm{kg} / \mathrm{m}^{3} \cdot \mathrm{s}\right]$ \\
\hline$\varepsilon$ & volume fraction, [-] \\
\hline$\eta$ & damping coefficient, $[\mathrm{N} \cdot \mathrm{s} / \mathrm{m}]$ \\
\hline$\mu$ & gas phase shear viscosity $[\mathrm{Pa} \cdot \mathrm{s}]$ \\
\hline$\mu_{f}$ & friction coefficient, [-] \\
\hline$\rho$ & density, $\left[\mathrm{kg} / \mathrm{m}^{3}\right]$ \\
\hline$\tau$ & stress tensor, $[\mathrm{Pa}]$ \\
\hline \multicolumn{2}{|c|}{ Subscripts } \\
\hline$a, p$ & particle \\
\hline$b$ & bubble \\
\hline
\end{tabular}




\begin{tabular}{|ll|}
$b c$ & bubble-to-cloud \\
$c e$ & bubble-to-emulsion \\
$A, B$ & cloud-to-emulsion \\
$g$ & gas component \\
$i, j$ & gas \\
$m b$ & component \\
$m f$ & minimum bubbling fluidization condition \\
$n$ & minimum fluidization condition \\
$t$ & normal direction \\
$w$ & tangential direction \\
inj & wake \\
diff & injection \\
& diffusion \\
Abbreviations & \\
CFD & computational fluid dynamics \\
DPM & discrete particle model \\
\hline & two-fluid model \\
\hline
\end{tabular}

\section{Introduction}

Gas-solid fluidized bed reactors are often applied in the process industries due to their excellent mixing and heat transfer characteristics. It is well-known that bubbles prevail in these beds and their dynamics are responsible for the solids agitation and the accompanying favorable heat and mass transfer characteristics of fluidized beds. An important foundation for a rational design of fluidized bed reactors is a thorough understanding of the mass transfer processes in fluidized beds, specifically the bubble-to-emulsion phase mass transfer. This phenomenon occurs via the combined effects of gas diffusion, coherent gas flow and solids motion carrying adsorbed gas atoms (Davidson and Harrison, 1963; Kunii and Levenspiel, 1991).

In the past decades, single-bubble fluidized beds and freely bubbling fluidized beds have been used to study the bubble-to-emulsion phase mass transfer, both experimentally and numerically (a.o. Patil et al. (2003); Deshmukh et al. (2007); Pavlin et al. (2007); Dang et al. (2013); Hernández-Jiménez et al. (2013)). Phenomenological models, used for the design of industrialscale reactors, can only provide reliable predictions when accurate mass transfer coefficients are 
used. Up to now, most of the correlations for these coefficients are based on (i) analytical considerations and (ii) experiments using invasive measurement techniques. Several problems arise with this approach. Firstly, various assumptions have been made in order to reduce the mathematical analysis, but the scope of their validity has not yet been analyzed in detail. Secondly, the invasive experimental techniques may disturb the flow and are limited only to point measurements. Noninvasive optical techniques (e.g. Müller et al. (2006); Roels and Carmeliet (2006); Pavlin et al. (2007); Dang et al. (2013)) have been developed in the mean time, but detailed understanding of the underlying mechanisms is still out of reach particularly due to the difficulties in measuring the gas concentration in the emulsion phase (Dang et al., 2013).

In this light, numerical simulations (i.e. computational fluid dynamics) can shed more light on the detailed process of interphase mass transfer. Patil et al. (2003); Hernández-Jiménez et al. (2013), for instance, used the Two Fluid Model (TFM, and Euler-Euler technique) and focused on fluidized beds using Geldart-B type particles. Patil et al. (2003) has indicated that the Davidson and Harrison (1963) model predicts the mass transfer for single injected bubbles reasonably well, but their results show an inconsistent bubble size evolution and tracer gas concentration compared to the experiments from Dang et al. (2013). Hernández-Jiménez et al. (2013), on the other hand, found good agreement with Davidson and Harrison (1963) model for single-injected bubbles, but found that using freely bubbling fluidized beds, the mass transfer coefficients were more than two times larger than predicted.

With higher-detail models, it will be possible to identify the most important aspects of the interphase mass transfer. While the TFM uses various assumptions to describe the emulsion phase rheology, in a discrete particle model (DPM, an Euler-Lagrange technique) the particleparticle interactions are taken into account deterministically. The DPM can therefore provide more detailed insight into the prevailing phenomena compared to the TFM model, and also allows the simulation of smaller particles (e.g. Geldart A type particles). Geldart-A type particles are often used in industrial fluidized beds (typically FCC catalyst) and are also of interest for the design of micro fluidized beds (e.g. Tan et al. (2014, 2016)).

In this work, a state-of-the-art DPM model extended with gas component conservation equations is used to characterize the interphase mass transfer processes in gas-solid fluidized beds consisting of Geldart B and Geldart A type particles. The model will be used to simulate single injected bubbles that rise through an incipiently fluidized bed, analogous to the experiments carried out by Patil et al. (2003) and Dang et al. (2013), but without the specific limitations inherent to these techniques. Besides, the tracer gas concentration in the emulsion phase will 
not be neglected but analyzed for the computation of the mass transfer coefficient.

This section continues with a short overview of the available correlations for the bubble-toemulsion phase mass transfer coefficient, which will be used in the comparison with the simulation results. Subsequently, the DPM model will be outlined, followed by a detailed analysis of mass transfer processes in Geldart B and, subsequently, Geldart A particles. The paper is then finalized with a discussion and conclusions.

\subsection{Phenomenological models for bubble-to-emulsion mass transfer}

In the literature, several correlations have been reported for the prediction of the mass transfer coefficient. In the derivation of these correlations, a gas cloud between a bubble and the emulsion (bulk) phase is usually assumed, originally deemed as a thin region surrounding the bubble with a relatively high solids holdup compared to the bulk emulsion. Davidson first suggested the existence of the gas cloud in gas-solid bubbling fluidized beds (Rowe et al., 1964). The pioneering model by Davidson and Harrison (1963) has been widely used in phenomenological models for large scale fluidized bed reactors. In this model, the total mass transfer consists of a convective flow from the bubbles to the emulsion phase and diffusion from the bubble to the cloud. Kunii and Levenspiel (1991) followed their approach and proposed an extension considering two consecutive transfer steps, namely the transfer from the bubble to the cloud and that from the cloud to the emulsion. Based on the stream function derived by Murray (1965), Chiba and Kobayashi (1970) assumed that the gas composition in the cloud and bubble is uniform and that the mass transfer limitation is largely governed by the diffusion through the surface between the cloud and the emulsion phases. Table 1 summarizes the equations for estimating the bubble-toemulsion mass transfer coefficient for the most popular phenomenological models, together with the main assumptions used in their derivation. 


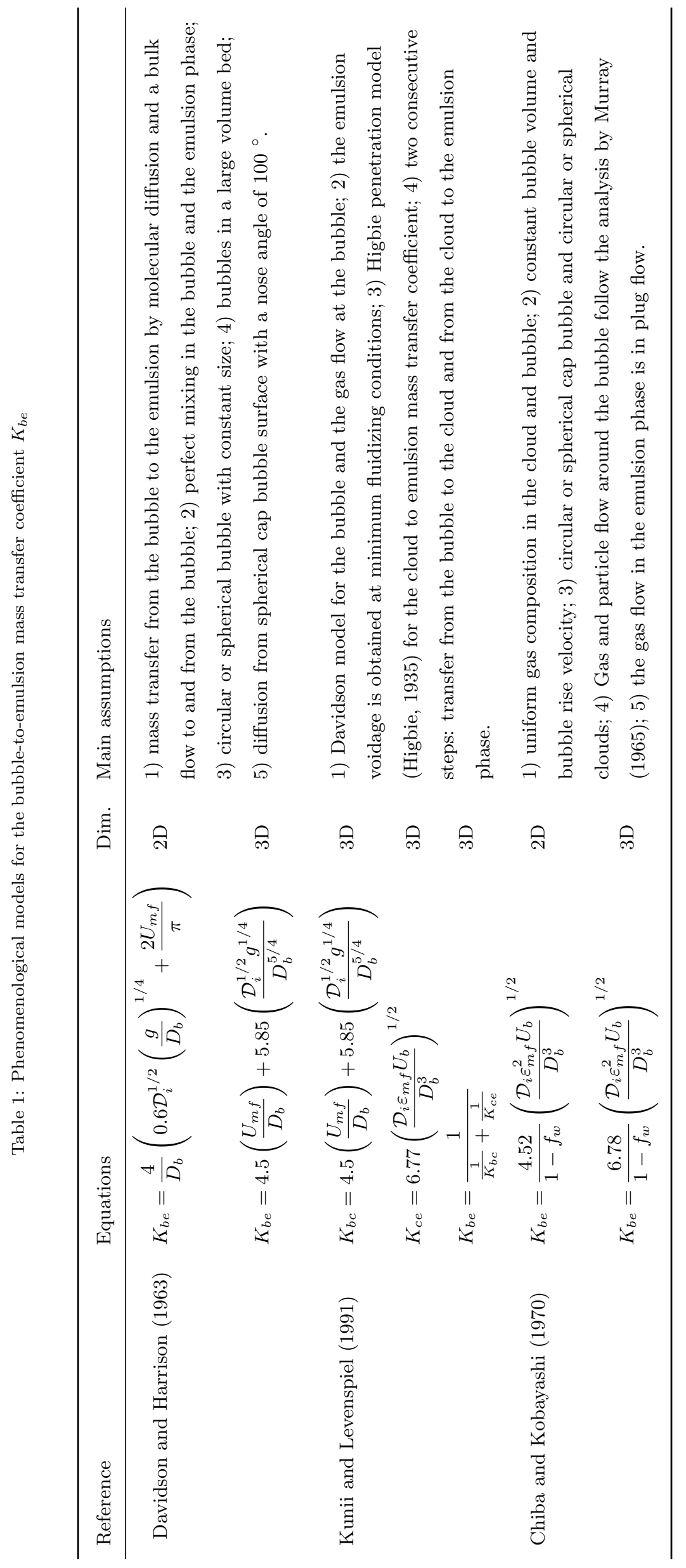




\section{Numerical method}

\subsection{The extended Discrete Particle Model}

The soft-sphere discrete particle model (DPM) employed in this study is based on the pioneering work by Tsuji et al. (1993) and has originally been developed by Hoomans et al. (1996) and Ye et al. (2004). It is a popular Euler-Lagrange type of model with a discrete description of the particulate phase and a continuous description of the gas phase, and has been widely used in hydrodynamic studies of gas-solid fluidized beds. A set of three dimensional volume-averaged Navier-Stokes equations for compressible flow are solved on the Eulerian grid cells for the gas phase hydrodynamics, assuming ideal gas behavior. For the particle phase, Newton's second law of motion is applied to each individual particle to trace its position and velocities while accounting for particle-particle and particle-wall collisions. Because the size of the Eulerian grid cells is larger than the particle diameter, the details of the interactions between the gas phase and the particles are unresolved and constitutive correlations are required to compute the momentum exchange between the two phases.

A summary of the main equations of the model used in this study is provided in Table 2 . For the gas-particle interaction the classic drag force correlation from Ergun (1952) and Wen et al. (1966) are utilized. The contact force resulting from particle-particle and/or particle-wall interactions is calculated using the linear spring and dashpot model proposed by Cundall et al. (1979). The particle spring stiffness constant is a key input parameter and it is common practice to use a value much smaller than the true one derived from material properties, since it allows an increased time step without noticeable effects on the hydrodynamics and thus reduces the required CPU time (Tsuji et al., 1993). Here, we choose those values such that the maximum overlap between interacting particles and particle-wall at any time step is less than $1 \%$ of the particle diameter. For a more detailed explanation of this model, we refer to our previous papers (Tan et al., 2014, 2016) and reviews by Deen et al. (2007) and Zhu et al. (2008).

The transport of chemical components is described using an instationary convection-diffusion equation for component $i$. For binary gas systems with components $A$ and $B$, Fick's law can be used for the molecular diffusion mass flux $\mathbf{j}_{i}=-\rho \mathcal{D}_{A B} \nabla y_{A}$, using $y_{A}$ to denote the mass fraction of component $A$, which is employed in the gas component conservation equation used in this study (Table 2).

The DPM has been extensively used for detailed understanding of hydrodynamic characteristics in gas-solid fluidized beds (for example, Xu et al. (1997); Li et al. (2007); Ye et al. (2004); 
Wang et al. (2010); Tan et al. (2014)). The extended part for the component conservation calculation is newly developed and its implementation has been carefully verified by carrying out simulations for simplified systems and comparing the results with theoretical solutions, as presented in Tan et al. (2016).

\subsection{Simulation configuration}

Investigations on the bubble-to-emulsion phase mass transfer have been carried out by simulating single-bubble injections of a tracer gas $\mathrm{CO}_{2}$ into a fluidized bed maintained at minimum fluidization (for beds using Geldart-B type particles) or minimum bubbling conditions (for beds using Geldart-A type particles). $\mathrm{N}_{2}$ was used as the background fluidization gas. After an initial $1 \mathrm{~s}$ of incipient fluidization, the bubble was injected by setting the central cells at the bottom boundary (the nozzle) to inflow of $\mathrm{CO}_{2}$ using a prescribed injection velocity. The cells were switched back to $\mathrm{N}_{2}$ at incipient fluidization velocity after the injection was finished. The injection time required for generating specific bubble sizes was determined by separate simulations beforehand.

A constant molecular (binary) diffusion coefficient of $\mathrm{CO}_{2}$ in $\mathrm{N}_{2}$ is used to describe the tracer gas diffusivity. For the Geldart-A type particle simulations, the diffusion coefficient of $\mathrm{CO}_{2}$ was also increased with a factor 3 to investigate the influence of the gas diffusivity. The nozzle for gas injection is located in the center of the bottom plate.

The simulations using Geldart-B type particles were set up based on the experiments done by Dang et al. (2013). The bed width of $4 \mathrm{~cm}$ was repeated from the experiments, which was subsequently supplemented with simulations using a bed width of $5 \mathrm{~cm}$ and $6 \mathrm{~cm}$. Similar to the experiments, the Geldart-B type particles have a density of $2525 \mathrm{~kg} / \mathrm{m}^{3}$ and average diameter of $500 \mu \mathrm{m}\left(400 \sim 600 \mu \mathrm{m}\right.$, Gaussian distribution with $\left.\sigma=5.0 \times 10^{-5}\right)$. The minimum fluidization velocity of these particles was determined by simulations using the pressure drop method at 0.22 $\mathrm{m} / \mathrm{s}(0.206 \mathrm{~m} / \mathrm{s}$ in the referenced paper). No-slip boundary conditions were applied to the side walls of the bed for these simulations.

The Geldart-A type particles employed in this study are monodispersed particles with a diameter of $100 \mu \mathrm{m}$ and density of $1500 \mathrm{~kg} / \mathrm{m}^{3}$. Van der Waals' forces is neglected in this study. Here the minimum bubbling fluidization velocity $\left(9.0 \times 10^{-3} \mathrm{~m} / \mathrm{s}\right)$, determined by simulations based on the standard deviation of the pressure drop over the bed, has been used as the background fluidization velocity. Since a large number of particles was used to allow the bubble some rising time, pseudo-2D fluidized beds are simulated to reduce the computational cost. The bed 
Gas phase continuity equation:

Gas phase momentum equation:

$$
\frac{\partial\left(\varepsilon_{g} \rho_{g}\right)}{\partial t}+\left(\nabla \cdot \varepsilon_{g} \rho_{g} \mathbf{u}_{g}\right)=0
$$

$$
\frac{\partial\left(\varepsilon_{g} \rho_{g} \mathbf{u}_{g}\right)}{\partial t}+\nabla \cdot\left(\varepsilon_{g} \rho_{g} \mathbf{u}_{g} \mathbf{u}_{g}\right)=-\varepsilon_{g} \nabla P_{g}-\mathbf{S}_{p}-\nabla \cdot\left(\varepsilon_{g} \tau_{g}\right)+\varepsilon_{g} \rho_{g} \mathbf{g}
$$

Gas phase equation of state:

$$
\rho_{g}=\frac{M_{g}}{R T} P_{g} \text { with } M_{g}=\left(\frac{y_{i}}{M_{i}}\right)^{-1}
$$

Gas phase stress tensor:

$$
\tau_{g}=\mu_{g}\left(\nabla \mathbf{u}_{g}+\nabla \mathbf{u}_{g}^{T}\right)-\left(\lambda_{g}-\frac{2}{3} \mu_{g}\right)\left(\nabla \cdot \mathbf{u}_{g}\right) \mathbf{I}
$$

Gas-solid momentum exchange rate:

$$
\beta= \begin{cases}\frac{3}{4} C_{D} \frac{\rho_{g} \varepsilon_{g}\left(1-\varepsilon_{g}\right)\left\|\mathbf{u}_{g}-\mathbf{v}_{a}\right\|}{d_{p}} \varepsilon_{g}^{-2.65} & \varepsilon_{g} \geq 0.8 \\ 150 \frac{\left(1-\varepsilon_{g}\right)^{2} \mu_{g}}{\varepsilon_{g} d_{p}^{2}}+1.75 \frac{\rho_{g}\left(1-\varepsilon_{g}\right)\left\|\mathbf{u}_{g}-\mathbf{v}_{a}\right\|}{d_{p}} & \varepsilon_{g}<0.8\end{cases}
$$

the porosity in DPM simulation:

$$
\varepsilon_{g, \text { cell }}=1-\frac{1}{V_{\text {cell }}} \sum_{\forall a \in \text { cell }} f_{\text {cell }}^{a} V_{p}^{a}
$$

Equations of motion for every particle:

$$
\begin{gathered}
m_{a} \frac{d \mathbf{v}_{a}}{d t}=m_{a} \frac{d^{2} \mathbf{r}_{a}}{d t^{2}}=-V_{a} \nabla P_{g}+\frac{V_{a} \beta}{\varepsilon_{p}}\left(\mathbf{u}_{g}-\mathbf{v}_{a}\right)+m_{a} \mathbf{g}+\mathbf{F}_{\text {contact }, a} \\
I_{a} \frac{d \omega_{a}}{d t}=\mathbf{T}_{a}
\end{gathered}
$$

Gas component conservation equations:

$$
\frac{\partial}{\partial t}\left(\varepsilon_{g} \rho_{g} y_{i}\right)+\nabla \cdot\left(\varepsilon_{g} \rho_{g} y_{i} \mathbf{u}_{g}\right)=\nabla \cdot\left(\varepsilon_{g} \rho_{g} \mathcal{D}_{i} \nabla y_{i}\right)
$$

closure equation for component $i=0: \quad y_{0}=1-\sum_{i=1}^{c} y_{i}$

$$
\text { viscosity of a gas mixture: } \begin{aligned}
\mu_{g} & =\sum_{i} \frac{x_{i} \mu_{i}}{\sum_{j} x_{i} \Phi_{i j}} \\
\Phi_{i j} & =\frac{\left[1+\left(\frac{\mu_{i}}{\mu_{j}}\right)^{1 / 2}\left(\frac{M_{j}}{M_{i}}\right)^{1 / 4}\right]^{2}}{\left[8\left(1+\frac{M_{i}}{M_{j}}\right)\right]^{1 / 2}}
\end{aligned}
$$


depth is only 6 times the particle diameter and hence a free-slip boundary condition was applied for the front and back walls.

For all the simulations, the pressure at the top outlet was specified as the atmospheric pressure (101325 Pa). Particles were initially regularly placed layer by layer at the bottom of the bed with a small random fluctuating translational and rotational velocity to make sure that the system was in an asymmetric fluidized state from the start. Table 3 summarizes the main parameters used in the simulations. The parameters in the DPM model for Geldart-B type particles, such as restitution coefficients and friction coefficient, were first tested with a simulation setting most close to one experiment from Dang et al. (2013). A good agreement was found with regard to the key phenomena and bubble size as function of time. Note that despite the great similarity, the simulations cannot be used for an exact one-to-one comparison with the experiments. The analysis and resulting mass transfer coefficient are very sensitive to the gas injection and bubble formation time, and Dang et al. (2013) used a very high injection velocity and stopped the injection before the bubble formation was completed. Also, their analysis for the bubble-toemulsion mass transfer coefficients started before the bubble is completely formed and detached. These aspects can be controlled much more accurately in the simulations and hence differ from the experiments.

\subsection{Mass transfer coefficient calculation}

The mass transfer coefficient $K_{b e}$ can be calculated from an integral mass balance of the tracer gas in the bubble (defined as an enclosed region with a porosity above a predefined threshold):

$$
\frac{d\left(C_{\mathrm{CO}_{2}, b} V_{b}\right)}{d t}=-K_{b e}\left(C_{\mathrm{CO}_{2}, b}-C_{\mathrm{CO}_{2}, e}\right) V_{b}
$$

In order to analytically solve Equation 1, the averaged tracer gas (in this case $\mathrm{CO}_{2}$ ) concentration in the emulsion phase is assumed negligible (thus set to zero). As presented in Dang et al. (2013), for a pseudo-2D bed having a single bubble with an initial averaged tracer gas concentration of $C_{C O_{2}, b}(0)$, with $C_{C O_{2}, e}=0$ and at $t=t_{0}: C_{C O_{2}, b}=C_{C O_{2}, b}(0)$, integration yields

$$
\frac{C_{C O_{2}, b}(t)}{C_{C O_{2}, b}(0)}\left(\frac{D_{b}(t)}{D_{b}(0)}\right)^{2}=\exp \left(-K_{b e} t\right)
$$

where $D_{b}(0)$ is the initial bubble diameter and $D_{b}(t)$ is the bubble diameter at time $t$. By plotting $\ln \left(C_{C O_{2}, b}(t) D_{b}^{2}(t) / C_{C O_{2}, b}(0) D_{b}^{2}(0)\right)$ as a function of time, the mass transfer coefficient $K_{b e}$ can be calculated from the slope of the linear correlation according to Equation 2. 
Table 3: Summary of the values for the main simulation parameters in DPM

\begin{tabular}{lcc}
\hline & Geldart-B type & Geldart-A type \\
Particle diameter $d_{p}, \mu \mathrm{m}$ & $400 \sim 600$ & 100 \\
Particle number $N_{p}$ & 72500 & 279000 \\
Particle density $\rho_{g}, \mathrm{~kg} / \mathrm{m}^{3}$ & 2525 & 1500 \\
Normal restitution coefficients $e_{n}$ & 0.97 & 0.95 \\
Tangential restitution coefficients $e_{t}$ & 0.33 & 0.95 \\
Friction coefficient (particle-particle/wall) $\mu_{f}$ & 0.1 & 0.3 \\
Normal spring stiffness $k_{n}, \mathrm{~N} / \mathrm{m}$ & 3500 & 28 \\
Tangential spring stiffness $k_{t}, \mathrm{~N} / \mathrm{m}$ & 1000 & 8 \\
CFD time step $t, \mathrm{~s}$ & $1.0 \times 10^{-5}$ & $1.0 \times 10^{-5}$ \\
Particle dynamics time step $t_{p}, \mathrm{~s}$ & $1.0 \times 10^{-6}$ & $3.6 \times 10^{-6}$ \\
Domain height, $\mathrm{m}$ & $1.5 \times 10^{-1}$ & $2.32 / 3.0 \times 10^{-2}$ \\
Domain width, $\mathrm{m}$ & $4.0,5.0,6.0 \times 10^{-2}$ & $6.0 \times 10^{-4}$ \\
Domain depth, $\mathrm{m}$ & $5.0 \times 10^{-3}$ & $90 \times 58 / 75 \times 2$ \\
Number of grid cells & $150 \times 40 / 50 / 60 \times 5$ & $1.65 / 4.95 \times 10^{-5}$ \\
Diffusivity of $\mathrm{CO}{ }_{2} \mathcal{D}_{\text {diff }}, \mathrm{m}^{2} / \mathrm{s}$ & $1.65 \times 10^{-5}$ & $0.1,0.2$ \\
Injection velocity $U_{\text {inj }}, \mathrm{m} / \mathrm{s}$ & $5.0,6.0$ & $0.035,0.036$ \\
Injection time $\Delta t_{\text {inj }}, \mathrm{s}$ & $0.07,0.075$ & $5.9 \times 10^{-3}$ \\
Nozzle area, $\mathrm{mm}^{2}$ & $20(4 \times 5$ grid cells $)$ & $0.96(4 \times 2$ grid cells $)$ \\
Minimum fludization velocity $U_{m f}, \mathrm{~m} / \mathrm{s}$ & 0.22 & $-0 \times 10^{-3}$ \\
Bubbling fluidization velocity $U_{m b}, \mathrm{~m} / \mathrm{s}$ & - &
\end{tabular}

\section{Fluidized beds using Geldart-B type particles}

\subsection{Characteristics of bubble-to-emulsion phase mass transfer}

The tracer gas concentration in the center slice of the fluidized bed is shown in Figure 1 for the simulation using a bed width of $6 \times 10^{-2} \mathrm{~m}$ and an injection velocity of $6 \mathrm{~m} / \mathrm{s}$. While the actual value is somewhat arbitrary, a porosity of 0.85 is used to define the bubble contour. In this figure, a range of porosity contours for the bubble is provided to show the pronounced phenomenon of particle raining which leads to bubble collapse. As found by Patil et al. (2003) and Dang et al. (2013), the bubble shape as well as the bubble size continue to change over time. The same holds for the tracer gas concentration inside the bubble. 


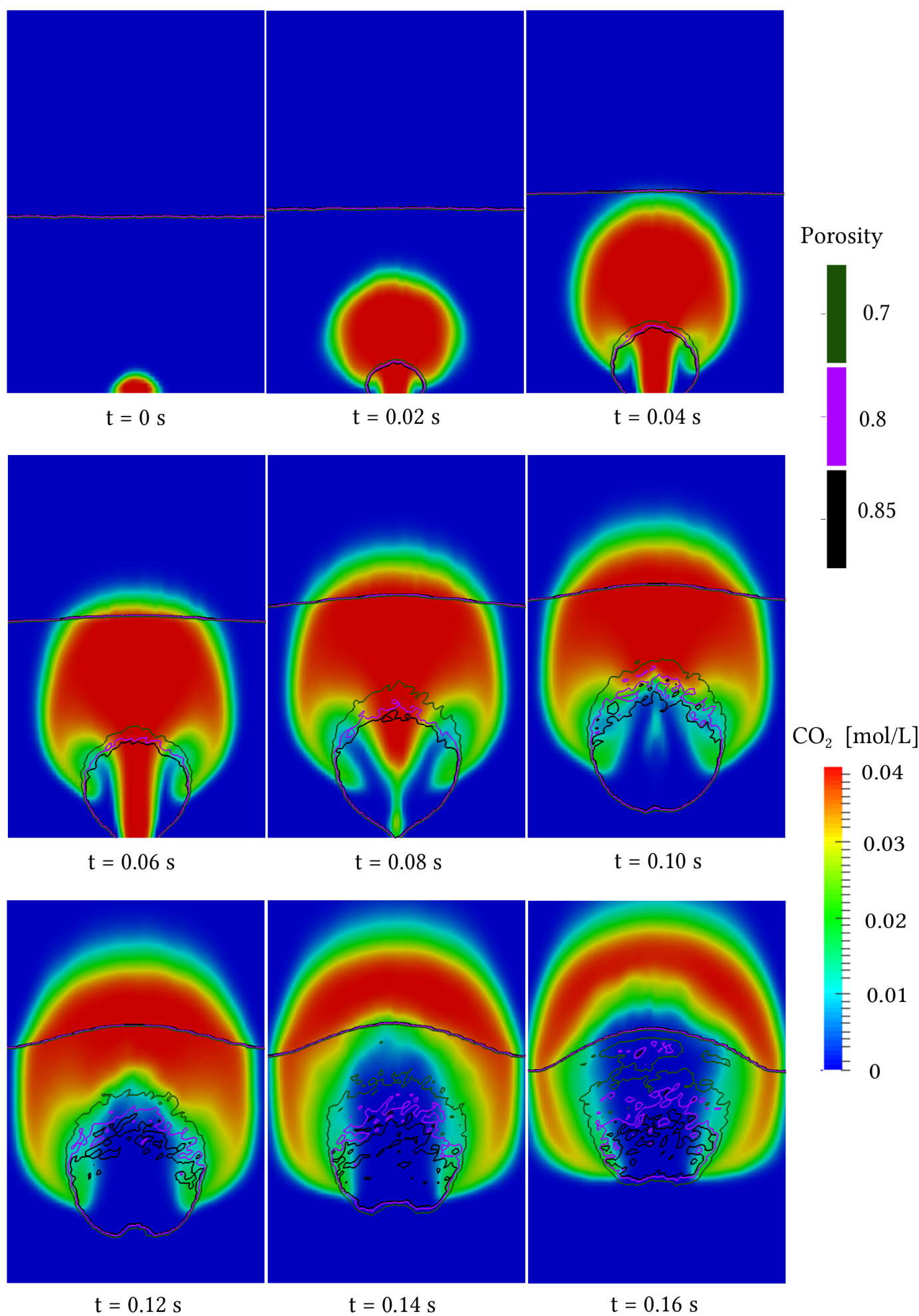

Figure 1: Snapshots of the tracer gas concentration in the center slice of the fluidized bed at different moments in time from the beginning of the injection (from $t=0 \mathrm{~s}$ to $0.16 \mathrm{~s}$ with a step of $0.02 \mathrm{~s}$ ), where the bubble is depicted with different threshold values of the porosity $12(0.7-0.85)$ (bed width $=6 \times 10^{-2} \mathrm{~m}, d_{p}=400 \sim 600$ $\left.\mu \mathrm{m}, U_{\mathrm{inj}}=6 \mathrm{~m} / \mathrm{s}, \Delta t_{\mathrm{inj}}=0.075 \mathrm{~s}\right)$. 


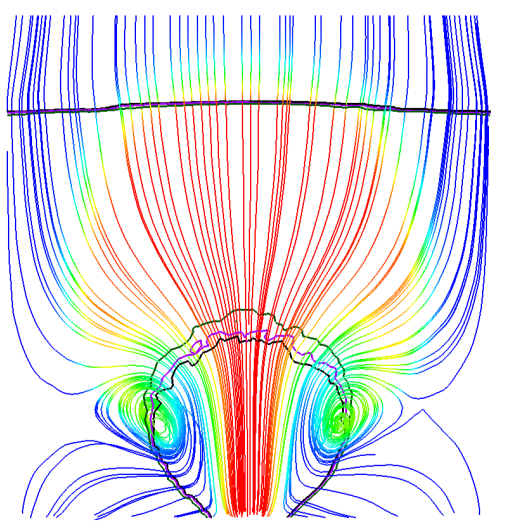

$\mathrm{t}=0.06 \mathrm{~s}$

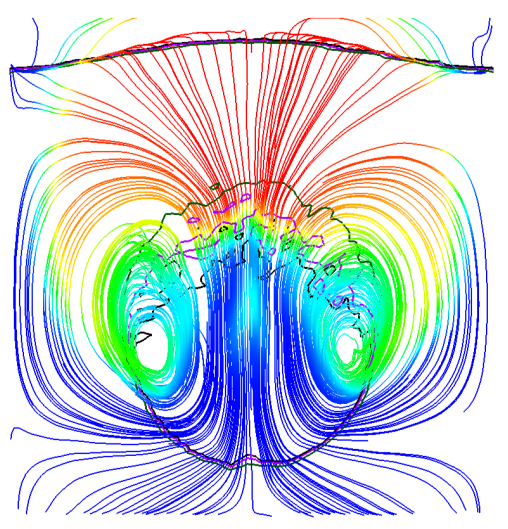

$\mathrm{t}=0.1 \mathrm{~s}$
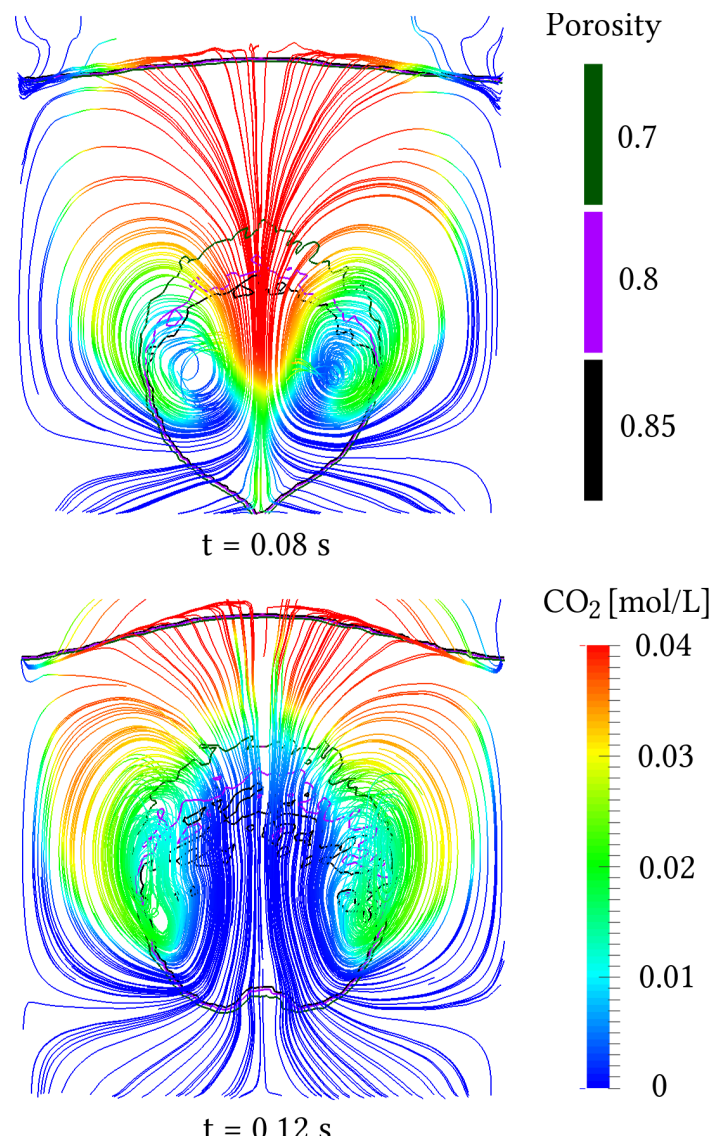

Porosity

Figure 2: Snapshots of the streamlines through the bubble in the center slice of a fluidized bed from $0.06 \mathrm{~s}$ to $0.12 \mathrm{~s}$ after the tracer gas injected (bed width $=6 \times 10^{-2} \mathrm{~m}, d_{p}=400 \sim 600 \mu \mathrm{m}, U_{\mathrm{inj}}=6 \mathrm{~m} / \mathrm{s}, \Delta t_{\mathrm{inj}}=0.075 \mathrm{~s}$ ). 


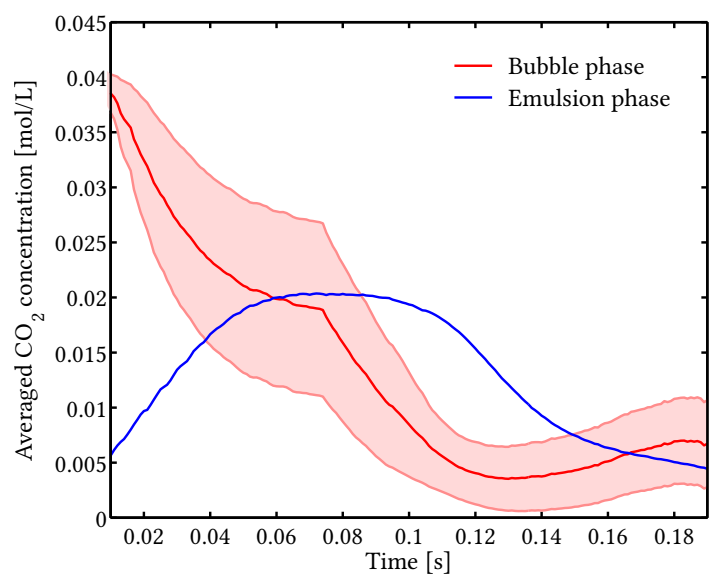

(a)

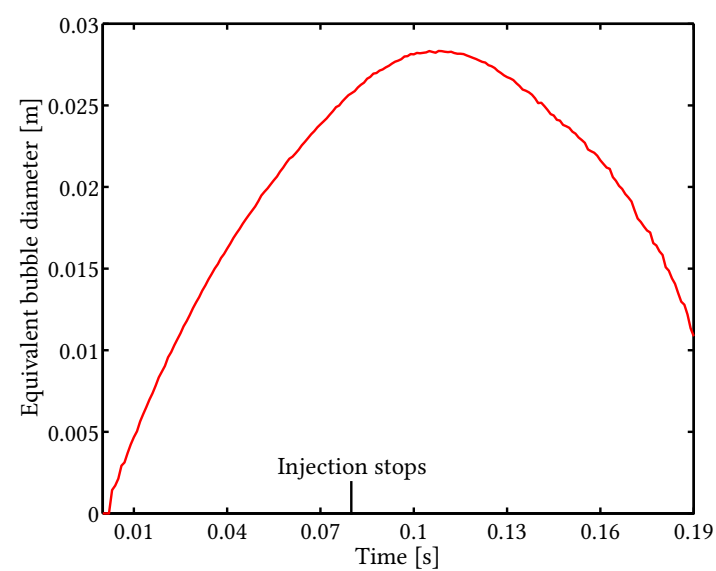

(b)

Figure 3: a) The average $\mathrm{CO}_{2}$ concentration in the emulsion phase and in the bubble with its spatial standard deviation (shaded bar) as a function of time; b) The equivalent bubble diameter as a function of time after the injection started (bed width $=6 \times 10^{-2} \mathrm{~m}, d_{p}=400 \sim 600 \mu \mathrm{m}, U_{\mathrm{inj}}=6 \mathrm{~m} / \mathrm{s}, \Delta t_{\mathrm{inj}}=0.075 \mathrm{~s}$ ).

From the snapshots in Figure 1 three stages can be discerned; first, it is noticed that the bubble starts to form shortly after the injection and the tracer gas appears at the nozzle even before the bubble is distinguishable. The gas flow trajectories, shown in Figure 2, indicate that both the tracer gas $\mathrm{CO}_{2}$ (via the middle) and the background fluidization gas $\mathrm{N}_{2}$ (via the bubble sides) contribute to the formation of the bubble, while the tracer gas $\mathrm{CO}_{2}$ immediately flows through the top of the bubble into the emulsion phase. After the bubble is formed, the second stage starts, where background fluidization gas $\mathrm{N}_{2}$ flows into the bubble also via the bottom and replaces the $\mathrm{CO}_{2}$ that continues to leave the bubble through its roof. In this Geldart B case, the mass transfer is thus strongly dominated by convection, as reported by Dang et al. (2013). A small part of the $\mathrm{CO}_{2}$ that leaves to the emulsion phase is recycled through the left and right vortices, back into the bubble (see Figure 2). During the last stage, the last traces of $\mathrm{CO}_{2}$ that are trapped in the vortices can only leave through diffusion; a slow process such that the bubble concentration remains fairly constant while it collapses, also shown by the experimental results from Dang et al. (2013).

Figure 3a shows the $\mathrm{CO}_{2}$ concentration in the bubble and emulsion phases, where also the three stages indicated above can be distinguished. The emulsion phase concentration is nonzero and at times even larger than the bubble concentration, but since the majority of $\mathrm{CO}_{2}$ is found downstream of the bubble (incapable of re-entering the bubble), the assumption of a 
a)

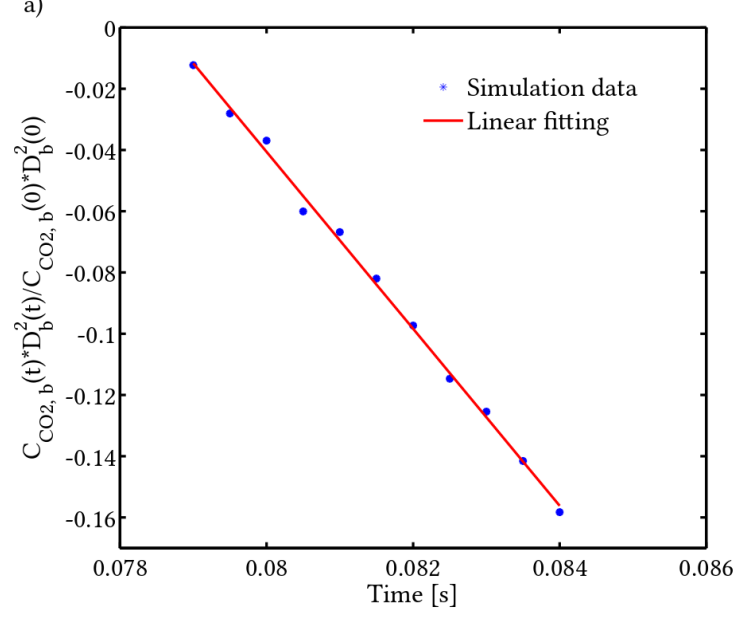

b)



Figure 4: The linearity correlations for the bubble-to-emulsion mass transfer coefficients for different cases using particles of $400 \sim 600 \mu \mathrm{m}$ in diameter: a) bed width $=5 \times 10^{-2} \mathrm{~m}, U_{\mathrm{inj}}=5 \mathrm{~m} / \mathrm{s}, \Delta t_{\mathrm{inj}}=0.07 \mathrm{~s}$ and $D_{b}=0.0231 \mathrm{~m}$; b) bed width $=6 \times 10^{-2} \mathrm{~m}, U_{\text {inj }}=6 \mathrm{~m} / \mathrm{s}, \Delta t_{\text {inj }}=0.075 \mathrm{~s}$ and $D_{b}=0.0277 \mathrm{~m}$.

negligible emulsion phase concentration to describe the bubble-to-emulsion phase mass transfer seems justified. Figure $3 \mathrm{~b}$ shows the equivalent bubble diameter $D_{b}=\sqrt{4 \frac{A_{b}}{\pi}}$, and shows that the bubble starts to collapse shortly after an initial growth, which is consistent with the experimental results from Dang et al. (2013). However, Patil et al. (2003) failed in predicting the decreasing bubble size at the later stage with 2D TFM simulations and presented a slow increase of the equivalent bubble diameter there, explaining the above described discrepancy.

\subsection{Bubble-to-emulsion phase mass transfer coefficient}

In the previous section, the assumption of taking a negligible emulsion concentration was justified, so Equation 2 can be employed to calculate $K_{b e}$. In order to exclude wall effects as much as possible, the evolution of the gas streamlines was studied to find the time before wall effects become dominant. Subsequently, $K_{b e}$ was obtained from the linearized Equation 2, using two different bubble sizes (Figure 4). Table 4 presents the comparison for $K_{b e}$ between the simulations and the predictions from the Davidson and Harrison (1963) model.

In Table 4, the differences between the values calculated from the simulations and the predictions using the Davidson and Harrison (1963) model are less than 10\%, showing a good agreement. The short time period used to calculate $K_{b e}$ allows making the relevant assumptions, such as constant bubble diameter, constant mass transfer coefficient and zero tracer gas in the emulsion phase. Table 4 also shows that the convective contribution is indeed dominant and that 
Table 4: Comparison of the simulated BE-MT coefficients with the predictions with the Davidson and Harrison (1963) model, including the individual contribution of diffusion and convection based mass transfer.

\begin{tabular}{|c|c|c|c|c|}
\hline \multirow[b]{2}{*}{ Cases } & \multirow{2}{*}{$\begin{array}{l}\text { Averaged bubble } \\
\text { diameter }[\mathrm{m}]\end{array}$} & \multicolumn{3}{|c|}{ Mass transfer coefficient $K_{b e}\left[s^{-1}\right]$} \\
\hline & & $\begin{array}{c}\text { Davidson and } \\
\text { Harrison model (1963) }\end{array}$ & This study & Difference \\
\hline $\begin{array}{c}\text { Bed width }=5 \mathrm{~cm} \\
U_{\mathrm{inj}}=5 \mathrm{~m} / \mathrm{s}\end{array}$ & 0.0231 & 27.08 (Conv $24.90+$ Diff 2.18) & 28.89 & $6.69 \%$ \\
\hline $\begin{array}{c}\text { Bed width }=6 \mathrm{~cm} \\
\qquad U_{\mathrm{inj}}=6 \mathrm{~m} / \mathrm{s}\end{array}$ & 0.0277 & $22.48($ Conv $20.75+$ Diff 1.74$)$ & 24.33 & $8.21 \%$ \\
\hline
\end{tabular}

the larger $K_{b e}$ is obtained for the smaller bubble, which is consistent with the results presented above and with previous studies (Patil et al., 2003; Dang et al., 2013).

\section{Fluidized beds using Geldart-A type particles}

The DPM technique is also very suitable to simulate Geldart A type particles, which are used in many industrial fluidization processes. In this section, particles with a diameter of $100 \mu \mathrm{m}$ with a density of $1500 \mathrm{~kg} / \mathrm{m}^{3}$ are used. Similar to the previous cases, single bubble injections are performed, using a porosity of 0.85 to define the bubble surface. The bubbles rise steadily through the bed until they break up at the bed surface.

\subsection{Characteristics of bubble-to-emulsion phase mass transfer}

Figure 5 shows the concentration field and gas phase streamlines for a simulation using an injection velocity of $0.1 \mathrm{~m} / \mathrm{s}$. The $\mathrm{CO}_{2}$ concentration in the middle of the bubble is relatively high. The $\mathrm{CO}_{2}$ transfered to the emulsion phase is found mainly in the path behind the bubble. This concentration profile is very similar to the profile of gas bubbles rising in a liquid (e.g. Stöhr et al. (2009)) with a tail behind the bubble.

The snapshots indicate a quite different mass transfer process from the one using GeldartB type particles. The gas phase streamlines recirculate inside the bubble and its immediate surroundings (the cloud), keeping the tracer gas local to the bubble. Also, no sign of bubble collapse is seen in the snapshots. These characteristics are highlighted in Figure 6, showing that the bubble even keeps growing while rising through the bed. A simulation with a 3 times higher tracer diffusivity, and otherwise identical settings, shows that the diffusivity of the gas has a 


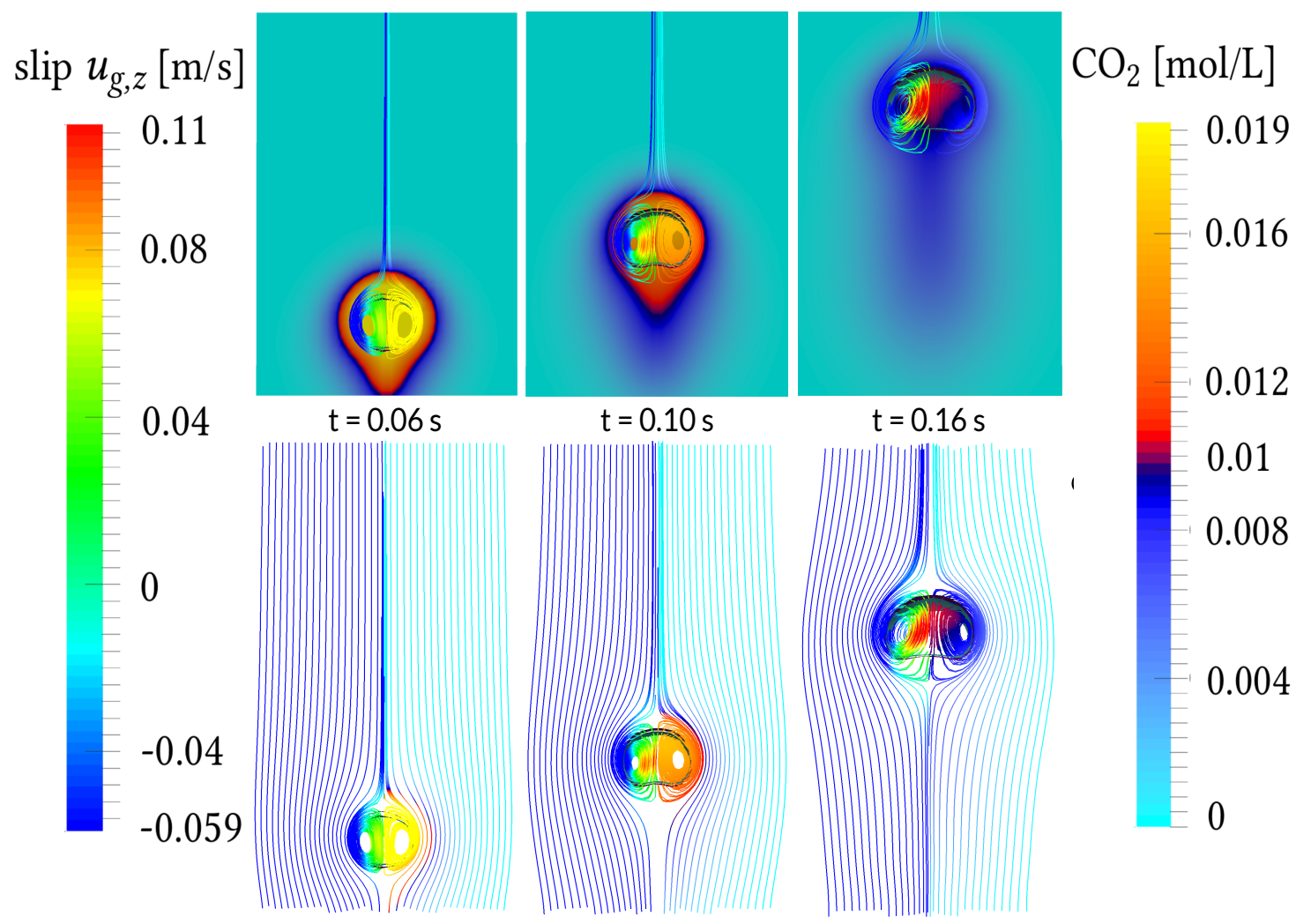

Figure 5: Snapshots of the rising bubble in Geldart A beds at different time steps. At the top, the $\mathrm{CO}_{2}$ concentration in the center slice is shown. The bubble is plotted by varying the threshold value of porosity from 0.8 to 0.85 . At the bottom, the streamlines of the relative gas phase in the bubble and the emulsion phases are shown. For top and bottom: the streamlines at the left half of the bubble are colored using the relative gas velocity in the $\mathrm{Z}$ direction while at the right half of the bubble are colored with the $\mathrm{CO}_{2}$ concentration. (bed width $=2.32 \times 10^{-2} \mathrm{~m}, d_{p}=100 \mu \mathrm{m}, U_{\text {inj }}=0.1 \mathrm{~m} / \mathrm{s}, \mathcal{D}_{\text {diff }}=1.65 \times 10^{-5} \mathrm{~m}^{2} / \mathrm{s}, \Delta t_{\text {inj }}=0.035 \mathrm{~s}$ ). 


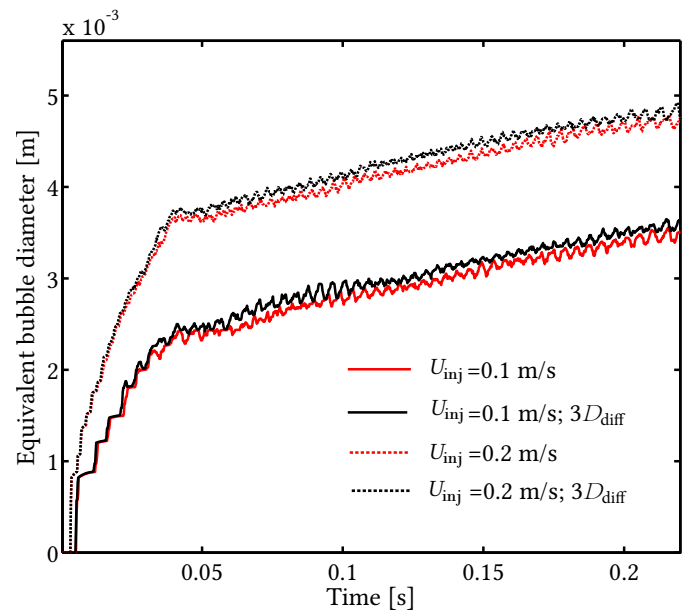

(a)

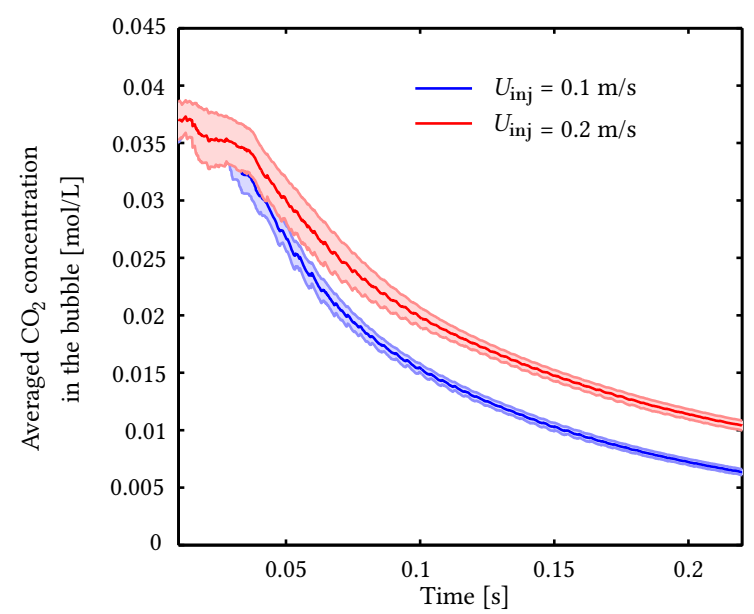

(b)

Figure 6: (a) The equivalent bubble diameter as a function of time after starting the injection with the tracer gases having different diffusivities of a factor 3 , and (b) The averaged $\mathrm{CO}_{2}$ concentration in the bubbles and its spatial deviation (shaded bar) as a function of time, in single-bubble fluidized beds using Geldart-A type particles $\left(d_{p}=100 \mu \mathrm{m}, \rho_{p}=1500 \mathrm{~kg} / \mathrm{m}^{3}, \mathcal{D}_{\text {diff }}=1.65 \times 10^{-5} \mathrm{~m}^{2} / \mathrm{s}, \Delta t_{\text {inj }}=0.035\right.$ and $\left.0.036 \mathrm{~s}\right)$.

negligible influence on the bubble size. The averaged $\mathrm{CO}_{2}$ concentration in the bubble keeps decreasing with time while it remains more or less uniformly distributed. Moreover, as shown in Figure 7, over time the averaged $\mathrm{CO}_{2}$ concentration in the emulsion phase is much lower than the averaged $\mathrm{CO}_{2}$ concentration in the bubble, and the mass transfer rate increases with increased diffusivity.

Based on the criteria for a clouded bubble presented in Davidson and Harrison (1963)'s book, these bubbles are surrounded by clouds. As shown in Figure 5, the gas flowing out of the bubble via its roof flows downwards along the bubble edge and circulates back through the cloud into the bubble. The main difference between the calculated gas flow at the bubble in Figure 5 and the predicted gas flow at a clouded bubble in Davidson and Harrison (1963)'s book are the bubble shape and the gas flow profiles in the wake of the bubble. In the theory, the bubble is assumed ideally spherical and no wake is defined, but the opposite is seen in the simulations.

\subsection{Bubble-to-emulsion phase mass transfer coefficient}

The streamlines shown in Figure 5 are actually quite similar to the predictions based on Murray (1965)'s theory, used by Chiba and Kobayashi (1970) for providing a correlation for the mass transfer coefficient (Figure 8). 


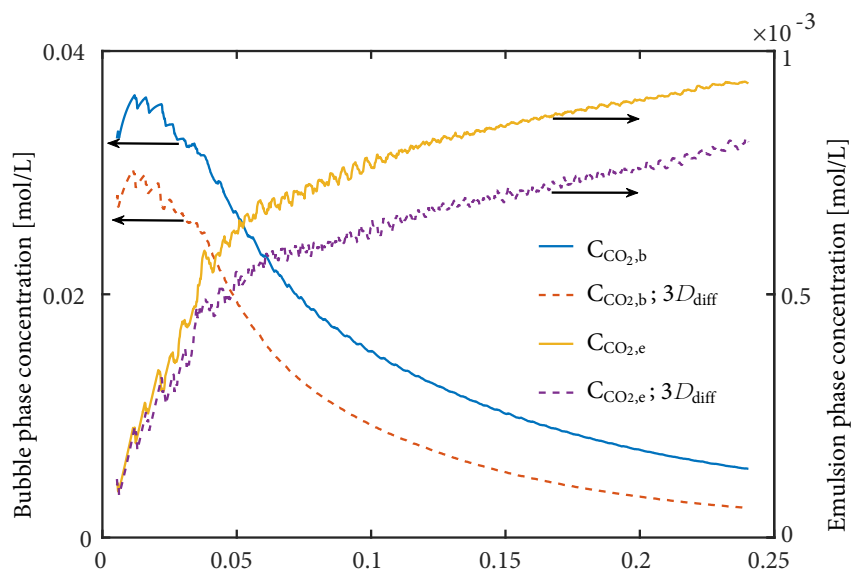

Figure 7: The averaged $\mathrm{CO}_{2}$ concentration in the bubble and emulsion phases in single-bubble fluidized beds using Geldart-A type particles and the tracer gases with different diffusivities of a factor $3\left(d_{p}=100 \mu \mathrm{m}, \rho_{p}=1500\right.$ $\left.\mathrm{kg} / \mathrm{m}^{3}, U_{\mathrm{inj}}=0.1 \mathrm{~m} / \mathrm{s}, \Delta t_{\mathrm{inj}}=0.035 \mathrm{~s}\right)$.

a)

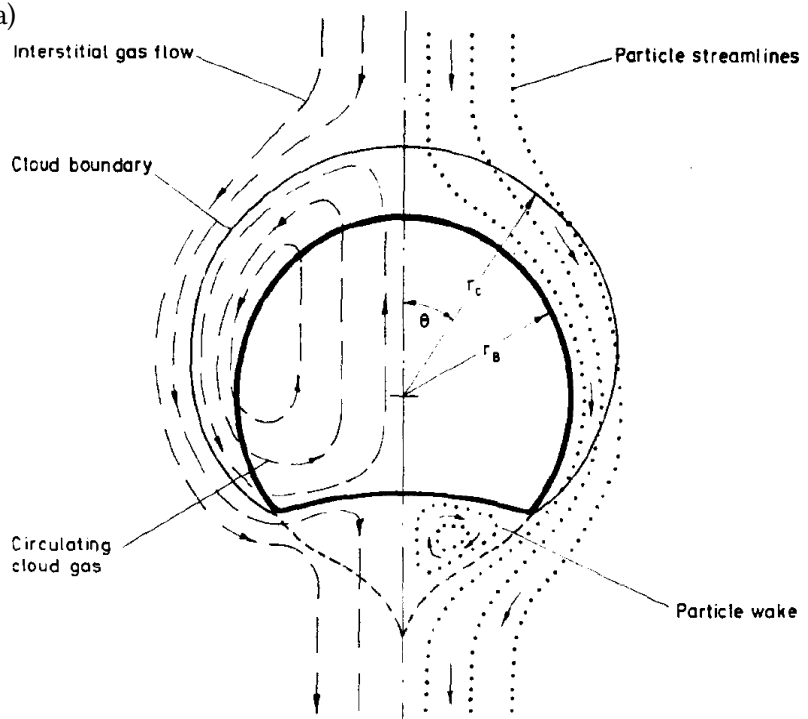

b)

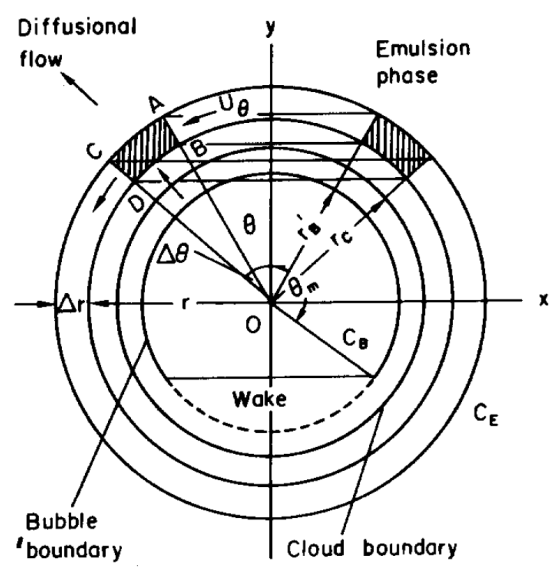

Figure 8: a) Gas and particle flow patterns near a bubble based on experiments and Murray's theory (Rowe et al., 1964) $(\alpha \simeq 2.5)$ and b) their symbolized model used by Chiba and Kobayashi (1970). 


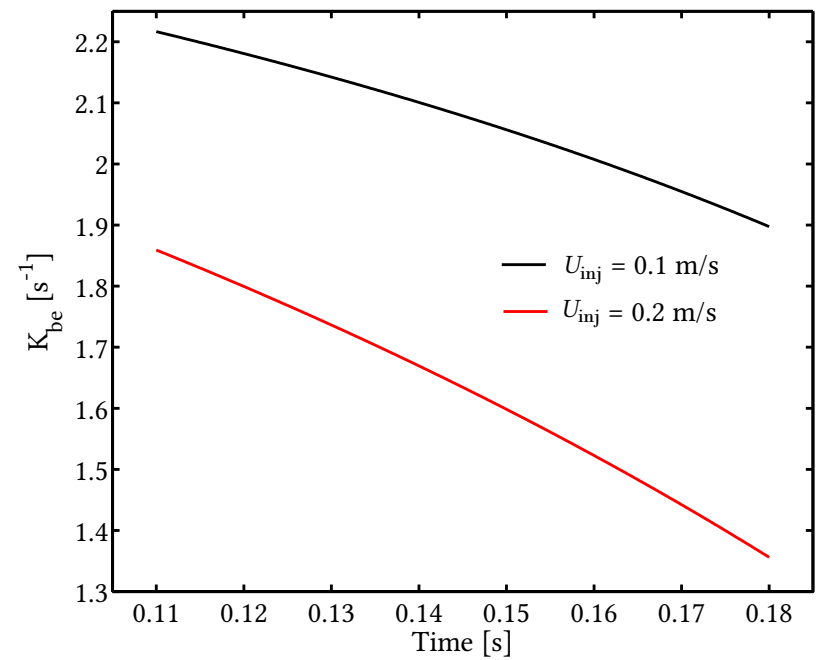

Figure 9: The bubble to emulsion phase mass transfer coefficient as a function of time calculated from the simulations of single injected bubble in a fluidized bed using Geldart-A type particles $\left(d_{p}=100 \mu \mathrm{m}, \rho_{p}=1500\right.$ $\mathrm{kg} / \mathrm{m}^{3}, U_{\text {inj }}=0.1$ and $0.2 \mathrm{~m} / \mathrm{s}, \Delta t_{\text {inj }}=0.035$ and $\left.0.036 \mathrm{~s}, \mathcal{D}_{\text {diff }}=1.65 \times 10^{-5} \mathrm{~m}^{2} / \mathrm{s}\right)$.

Equation 1 is used to calculate $K_{b e}$, based on the average $\mathrm{CO}_{2}$ concentration in the whole emulsion phase, as a function of time. Figure 9 shows that while the bubble rises, $K_{b e}$ decreases with time as a result of bubble growth (Figure 6a). Together with the averaged bubble diameter, the time-averaged $K_{b e}$ are presented in Table 5 ("bulk emulsion" column) and compared with predictions from classic phenomenological models: D\&H (Davidson and Harrison, 1963), K\&L (Kunii and Levenspiel, 1991) and C\&K (Chiba and Kobayashi, 1970). The large differences in the predictions of $K_{b e}$ and these models are related to the differences in the underling assumptions. Note that the bubble rise velocity $U_{b}$ calculated from simulation results has been used in the computation of $K_{b e}$ with these phenomenological models.

Despite the similarity between the gas streamlines (Figure 5) and the theory of Murray (1965) (Figure 8) utilized in the Chiba and Kobayashi (1970) model, the Chiba and Kobayashi (1970) model did not give the best prediction of the $K_{b e}$ for these simulations. This is most probably due to the fact that the phenomena observed in the simulations are not consistent with the assumptions for the process used in the derivation of Chiba and Kobayashi (1970) model, such as constant bubble volume (hence cloud volume) and the spherical shape and size of the cloud.

The influence of the varying bubble diameter on the averaged $K_{b e}$ has been analyzed first. The change in the amount of tracer gas in the bubble consists of two parts: a contribution due to the changing bubble size and a contribution related to the changing $\mathrm{CO}_{2}$ concentration in the 
Table 5: Comparison of mass transfer coefficients $K_{b e}$ computed from the simulation results and from phenomenological models.

\begin{tabular}{|c|c|c|c|c|c|c|c|}
\hline \multirow{2}{*}{$\begin{array}{c}U_{\mathrm{inj}} \\
{[\mathrm{m} / \mathrm{s}]}\end{array}$} & \multirow{2}{*}{$\begin{array}{c}D_{b} \\
{[\mathrm{~m}]}\end{array}$} & \multicolumn{3}{|c|}{$K_{b e}[1 / \mathrm{s}]$ (predictions) } & \multicolumn{3}{|c|}{$K_{b e}[1 / \mathrm{s}]$ (simulations) } \\
\hline & & $\mathrm{D} \& \mathrm{H}$ & $\mathrm{K} \& \mathrm{~L}$ & $\mathrm{C} \& \mathrm{~K}$ & bulk emulsion & $62.5 \% C_{b}$ & $73 \% C_{b}$ \\
\hline \multicolumn{8}{|c|}{ Diffusion coefficient $=1.65 \times 10^{-5}$} \\
\hline 0.1 & 0.003 & 27.37 & 11.85 & 16.93 & 2.07 & 10.61 & 15.36 \\
\hline 0.2 & 0.004 & 18.64 & 7.74 & 10.61 & 1.63 & 9.30 & 13.55 \\
\hline \multicolumn{8}{|c|}{ Diffusion coefficient $=4.95 \times 10^{-5}$} \\
\hline 0.1 & 0.003 & 42.34 & 19.12 & 28.11 & 4.33 & 20.48 & 29.16 \\
\hline 0.2 & 0.004 & 28.98 & 12.66 & 17.88 & 3.47 & 14.42 & 19.60 \\
\hline
\end{tabular}

bubble. Therefore, the analysis has been carried out for these two terms seperately. It turns out that the first term contributes over $60 \%$ to the total change in the amount of $\mathrm{CO}_{2}$ in the bubble.

Equation 1 computes the total mass transfer based on the mass transfer coefficient and the driving force, defined as the concentration difference between the bubble and the emulsion phase in the rest of the bed. However, as shown in Figure 5 a more accurate driving force could be the concentration difference between the bubble and the emulsion phase around the bubble (or the cloud). Here, the emulsion around the bubble with $\mathrm{CO}_{2}$ concentration larger than $62.5 \%$ and $73 \%$ (corresponding to different cloud sizes) of the average $\mathrm{CO}_{2}$ concentration in the bubble has been identified and its average $\mathrm{CO}_{2}$ concentration has been used to calculate $K_{b e}$. This gives a much more local emulsion phase concentration than the average over the entire bed. As shown in Table 5 , the computed $K_{b e}$ in columns named " $62.5 \% C_{b}$ " and " $73 \% C_{b}$ ", using the $\mathrm{CO}_{2}$ concentration in the surroundings of the bubble for the driving force, are in much better agreement with the predictions from the Kunii and Levenspiel (1991) and Chiba and Kobayashi (1970) models.

\section{Discussion and Conclusions}

\subsection{Discussion}

The simulation snapshots and analysis have shown that the mass transfer process is greatly influenced by the gas flow pattern at and around the bubble. As learned from Davidson and Harrison (1963)'s book, the gas flow pattern at the bubble is determined by the ratio of the bubble rise velocity to the interstitial gas velocity $\left(U_{b} / u_{0}\right)$. For slowly rising bubbles $\left(U_{b} / u_{0}<1\right)$ in 
single-bubble fluidized beds using Geldart-B type particles, the mass transfer is determined by the convective flow from the emulsion to the bubble and from the bubble back to the emulsion. The simulations in this work have shown that the tracer gas in the bubble transfers into the emulsion phase firstly by the (convective) depletion of the center of the bubble and then by the diffusion via the vortices at the left and right sides of the bubble before it collapses. Because the injected tracer gas escaped through the bubble, the emulsion phase concentration could be assumed to be zero. An important issue remains, however, on how the upstream concentration profile can be incorporated in the correlations, especially if it is not uniform. Any tracer gas that exists upstream (i.e. below the bubble) will likely travel towards the bubble, enter via the bottom and leave through the roof. This aspect of mass transfer is not captured in existing correlations, but is crucial for freely bubbling fluidized beds.

For fast rising bubbles $\left(U_{b} / u_{0} \simeq 5\right)$ in fluidized beds using Geldart-A type particles, the phenomena observed in the mass transfer process are quite different from the Geldart-B simulations. No obvious volumetric flow-rate between the bubble and the emulsion bulk was observed, rather a strong gas circulation in the bubble and the local emulsion phase (i.e. cloud) has been distinguished. Some of the tracer gas was left behind via the wake at the bottom of the bubble, but also a large part of the tracer gas was trapped in the bubble and was released only when the bubble broke up at the bed surface. The mass transfer coefficients computed with the theoretical models do not agree with those found from the simulations, unless a local emulsion phase concentration is taken into account. While the local emulsion phase concentration is clearly the most influential zone, and using a local emulsion phase concentration can be justified, it is important to acknowledge that the theoretical models are typically used for freely bubbling fluidized beds. Bubble breakup and coalescence can greatly increase the mass transfer between the bubble and emulsion phases. This may give a good additional explanation on why $K_{b e}$ calculated from the simulation results are much lower than any of the predictions from the phenomenological models derived for freely bubbling fluidized beds. The scope of this study, however, remains with single rising bubbles.

The used correlations incorporate the diffusion coefficient by including $\mathcal{D}_{i}^{0.5}$ in the diffusive terms. Increasing the diffusion coefficient by a factor 3 would therefore predict an increased mass transfer coefficient by a factor of $3^{0.5}=1.73$; however, the simulations typically yield a factor 2 larger mass transfer coefficient, showing that the effect of the diffusive flux is more important than anticipated by the correlations. 


\subsection{Conclusions}

A discrete particle model extended with gas component conservation equations has been used to investigate the bubble-to-emulsion phase mass transfer by carrying out simulations on singlebubble fluidized beds using both Geldart-A and -B type particles. New insights on the spatial distribution and temporal evolution of the tracer gas concentration in the bubble as well as in the emulsion have been developed. Detailed information on changes of the bubble size, tracer gas concentrations and the gas flow at the bubble are utilized to accurately analyze the mass transfer characteristics and calculate the mass transfer coefficient.

This work has challenged the validity of the assumptions used in popular phenomenological models for the bubble-to-emulsion mass transfer coefficient. For single-bubble fluidized beds using Geldart-B type particles, the bubble to emulsion phase mass transfer process is dominated by the convective gas flow from the emulsion phase to the bubble phase and then back to the emulsion phase. No uniform gas concentration in the bubble, or a constant bubble size and shape can be assumed for these cases.

The Davidson and Harrison (1963) model assumes a constant volumetric flow-rate into the bubble from the emulsion bulk and out of the bubble into the emulsion bulk. Since convective transfer is dominant (by far) for Geldart-B particles, this model predicts reasonably good mass transfer coefficients for these particles, provided that a constant bubble size and zero tracer gas concentration in the emulsion phase can be assumed. The first assumption is assured by taking a short time interval (keeping the size relatively constant), and the concentration in the emulsion phase could be assumed zero because the tracer gas concentration profile extends only downstream of the bubble. In freely bubbling fluidized beds, however, upstream concentration profiles may exist upstream of a bubble, which should then be taken into account.

For Geldart A type particles, the bubbles cannot be assumed to be constant in size and circular (or spherical) in shape, and it was shown that the bubble-to-emulsion mass transfer coefficient changes over time. These findings confirm and extend the findings from previous experimental and numerical studies. Not all tracer gas is ultimately exchanged with the emulsion inside the beds, but quite some is released at the bed surface when the bubbles break up. Hence, a proper definition of the cloud around the bubble and using the average tracer gas concentration in the cloud are necessary to calculate the mass transfer coefficient. In this case, the Kunii and Levenspiel (1991) and Chiba and Kobayashi (1970) models give the best predictions. Moreover, it has been demonstrated that gas diffusivity has a distinctive influence on the bubble-to-emulsion mass transfer in the beds, which is underestimated by the models. 


\section{Acknowledgments}

This project is financially supported by the Netherlands Organization for Scientific Research (NWO), STW VIDI Grant No. 10244.

\subsection{Reference}

T. Chiba, H. Kobayashi. 1970. Gas exchange between the bubble and emulsion phases in gas-solid fluidized beds. Chemical Engineering Science, 25, 1375-1385.

Cundall P.A., Strack O.D.L., 1979. A discrete numerical model for granular assemblies. Gotechniques $29,47-65$.

J.F. Davidson, D. Harrison. 1963. Fluidised particles. Cambridge university press Cambridge, UK.

Deen, N.G., van Sint Annaland, M., van der Hoef, M.A., Kuipers, J.A.M. 2007. Review of discrete particle modeling of fluidized beds. Chemical Engineering Science 62, 28-44.

N.T.Y. Dang, T. Kolkman, F. Gallucci, M. van Sint Annaland. 2013. Development of a novel infrared technique for instantaneous, whole-field, non invasive gas concentration measurements in gas-solid fluidized beds. Chemical Engineering Journal, 219, 545-557.

S.A.R.K. Deshmukh, M. van Sint Annaland, J.A.M. Kuipers. 2007. Gas back-mixing studies in membrane assisted bubbling fluidized beds. Chemical Engineering Science, 62, 4095-4111.

Ergun, S. 1952. Fluid flow through packed bed columns. Chemical Engineering Progress 48, 89-94.

R. Higbie. 1935. The rate of absorption of a pure gas into still liquid during short periods of exposure. Meeting transaction of the American institute of Chemical Engineers.

Hoomans, B.P.B., Kuipers, J.A.M., Briels, W.J., van Swaaij, W.P.M., 1996. Discrete particle simulation of bubble and slug formation in a two-dimensional gas-fluidized bed: a hard-sphere approach. Chemical Engineering Science 51, 99-118.

F. Hernández-Jiménez, A. Gómez-García, D. Santana, A. Acosta-Iborra. 2013. Gas interchange between bubble and emulsion phases in a $2 \mathrm{~d}$ fluidized bed as revealed by two-fluid model simulations. Chemical Engineering Journal, 215, 479-490.

Kunii, D., Levenspiel, O. 1991. Fluidization engineering, 2nd Edition. Butterworth-Heinemann. 
Li, J., Kuipers, J.A.M., 2007. Effect of competition between particle-particle and gas-particle interactions on flow patterns in dense gas-fluidized beds. Chemical Engineering Science 62, 3429-3442.

J.D. Murray. 1965. On the mathematical of fluidization Part 2. steady motion of fully developed bubbles. Journal of Fluid Mechanics, 22, 57-80.

Mohsen, M.F.N., Baluch, M.H., 1983. An analytical solution of the diffusion-convection equation over a finite domain. Applied mathematical modelling 7, 285-287.

C.R. Müller, J.F. Davidson, J.S. Dennis, P.S. Fennell, L.F. Gladden, A.N. Hayhurst, M.D. Mantle, A.C. Rees, A.J. Sederman.2006. Real-time measurement of bubbling phenomena in a three-dimensional gas-fluidized bed using ultrafast magnetic resonance imaging. Physical review letters, 96, 154504 .

Patil D.J., van Sint Annaland, M., Kuipers, J.A.M. 2003. Gas dispersion and bubble-to-emulsion phase mass exchange in a gas-solid bubbling fluidized bed: a computational and experimental study. International Journal of Chemical Reactor Engineering 1.

Pavlin, T., Wang, R., McGorty, R., Rosen, M.S., Cory, D.G., Candela, D., Mair, R.W., R.L. Walsworth. 2007. Noninvasive measurements of gas exchange in a three-dimensional fluidized bed by hyperpolarized 129Xe NMR. Applied Magnetic Resonance, 32, 93-112.

P.N. Rowe, B.A. Partridge, E. Lyall, 1964. Cloud formation around bubbles in gas fluidized beds. Chemical Engineering Science, 19, 973-985.

Roels, S., Carmeliet, J., 2006. Analysis of moisture flow in porous materials using microfocus X-ray radiography. International journal of heat and mass transfer, 49, 4762-4772.

M. Stöhr, J. Schanze, A. Khalili. 2009. Visualization of gas-liquid mass transfer and wake structure of rising bubble using pH-sensitive PLIF. Experiments in fluids, 47, 135-143.

Tsuji, Y., Kawaguchi, T., Tanaka, T. 1993. Discrete particle simulation of two-dimensional fluidized bed. Powder Technology 77, 79-87.

Tan, L., Roghair, I., van Sint Annaland, M. 2014. Simulation study on the effect of gas permeation on the hydrodynamic characteristics of membrane-assisted micro fluidized beds. Applied Mathematical Modelling 38, 4291-4307. 
Tan, L., Roghair, I., van Sint Annaland, M. 2016. Discrete particle simulations of micro membrane-assisted fluidized beds with $\mathrm{H}_{2}$ extraction. International Journal of Hydrogen Energy $41,8719-8731$.

Wen, Y.C., Yu, Y.H. 1966. Mechanics of fluidization. Chemical Engineering Progress Symposium Series $62,100-111$.

G.B. Wallis. 1969. One-dimensional two-phase flow. McGraw-Hill, New York.

Wang, J., van der Hoef, M., Kuipers, J.A.M. 2010. CFD study of the minimum bubbling velocity of Geldart A particles in gas-fluidized beds. Chemical Engineering Science 65, 3772-3785.

Xu, B.H., Yu, A.B, 1997. Numerical simulation of the gas-solid flow in a fluidized bed by combining discrete particle method with computational fluid dynamics. Chemical Engineering Science $52,2785-2809$.

Ye, M., van der Hoef, M., Kuipers, J.A.M. 2004. A numerical study of fluidization behavior of Geldart A particles using a discrete particle model. Powder Technology 139, 129-139.

Zhu, H.P., Zhou, Z.Y., Yang, R.Y., Yu, A.B., 2008. Discrete particle simulation of particulate systems: A review of major applications and findings. Chemical Engineering Science 63, 57285770. 